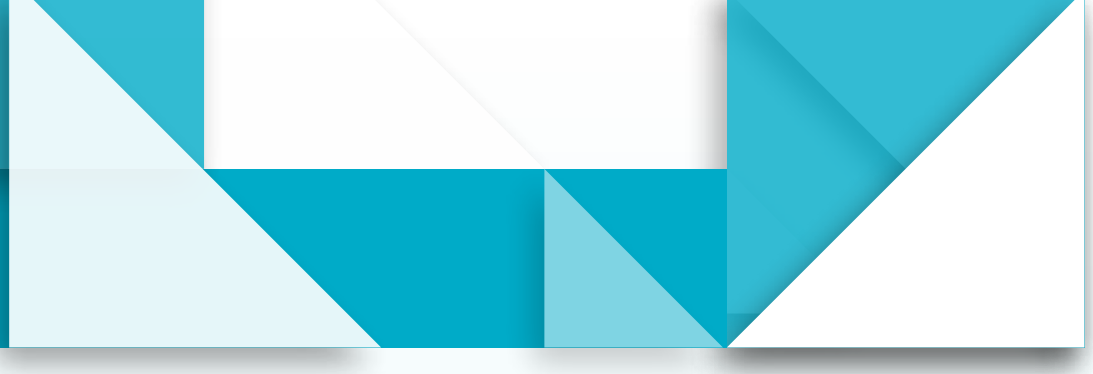

\title{
Educación científica 13 intercultural: tendiendo puentes conceptuales sobre las Pléyades en el Gran Chaco
}

- Intercultural Scientific Education: Building Conceptual Bridges about the Pleiades in the Gran Chaco

\section{Geraldine Chadwick* Leonor Bonan**}

- Educação científica intercultural: construindo pontes conceituais sobre as Plêiades no Gran Charco

\section{Resumen}

Este trabajo presenta los resultados de investigación de una tesis de Maestría en Enseñanza de las Ciencias Naturales. Para su realización se intervino en escuelas medias a las que asisten estudiantes, mayoritariamente de la etnia Qom. Siendo parte de una investigación-acción sobre Educación Científica Intercultural (ECI) y la Didáctica de las Ciencias Naturales (DCN), su objetivo específico fue encontrar los vínculos o puentes conceptuales entre los conocimientos científicos y los conocimientos vernáculos a través de una temática común. Para ello se diseñaron actividades exploratorias a través de las que se evaluó la presencia de elementos culturales científicos y vernáculos sobre las Pléyades, un grupo de estrellas muy significativo para las poblaciones amerindias. Con base a los resultados obtenidos en dichas actividades se obtuvo una clasificación de los principales actores y figuras que componen el cielo qom, develando el lugar de relevancia de las Pléyades en la bóveda celeste ancestral.

Palabras clave

educación científica intercultural; didáctica de las ciencias naturales; vínculos;

las Pléyades; etnia Qom

\footnotetext{
* Instituto de Investigaciones CeFIEC, FCEN, UBA. geralchad@ccpems.exactas.uba.ar

** Instituto de Investigaciones CeFIEC, FCEN, UBA lbonan@de.fcen.uba.ar
}
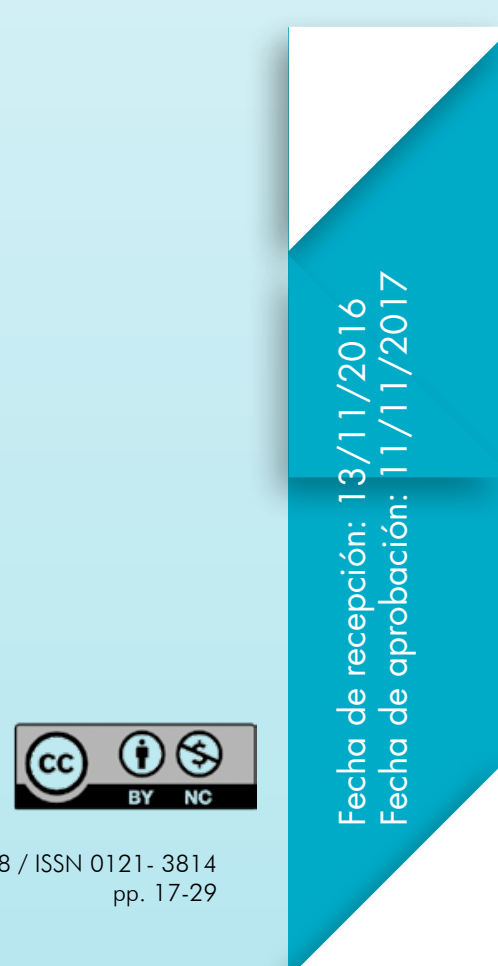


\section{Abstract}

This paper presents the research results of a final dissertation from the Master of Natural Sciences Education. To that end, we went to middle schools where most of the attending students are from the Qom ethnic group. As part of a research-action on Intercultural Scientific Education (ISE) and Natural Sciences Education (NSE), the main goal was to find conceptual links or bridges between scientific knowledge and vernacular knowledge through a common subject. For that purpose, we designed exploratory activities to evaluate the presence of scientific and vernacular cultural elements about the Pleiades, a very significant star cluster for Amerindian people. Based on the results obtained in these activities, we obtained a classification of the main actors and figures of the Qom sky, revealing the relevant place of the Pleiades in the ancestral sky.

\section{Keywords}

Intercultural scientific education; teaching natural sciences; links; the Pleiades; Qom people

\section{Resumo}

Este trabalho apresenta os resultados de pesquisa de uma tese de Mestrado em Ensino das Ciências Naturais. Para sua elaboração, trabalhou-se com escolas médias nas que estudam alunos maioritariamente da etnia Qom. Sendo parte de uma pesquisa-ação sobre Educação Científica Intercultural (ECI) e a Didática das Ciências Naturais (DCN), seu objetivo específico foi encontrar os vínculos ou as pontes conceituais entre conhecimentos científicos e os conhecimentos vernáculos através de uma temática comum. Para isso foram propostas atividades exploratórias através das que foi avaliada a presença de elementos culturais científicos e vernáculos sobre as Plêiades, um grupo de estrelas muito significativo para as populações ameríndias. Com base nas descobertas obtidas dessas atividades, realizou-se uma classificação dos principais atores e figuras que compõem o céu Qom, desvelando o lugar de relevância das Plêiades na esfera celeste ancestral.

Palavras-chave

educação científica intercultural; didática das ciências naturais; vínculos. as Plêiades; etnia Qom 


\section{Introducción}

Esta investigación se enmarca en el cruce de la didáctica de las ciencias naturales (DNC) y la educación científica intercultural (ECI), y busca promover la generación de una enseñanza de las ciencias que incluya las cosmovisiones de los pueblos originarios. El objetivo principal de este trabajo de investigación es develar qué puentes conceptuales permiten poner en comunicación conocimientos científicos y vernáculos sobre una misma temática científica. El fin último de este conocimiento pretende contribuir con la generación de prácticas significativas para las poblaciones aborígenes, en especial, de nuestro país. Se eligió como temática las Pléyades, un cúmulo abierto estelar de gran significatividad para las poblaciones aborígenes latinoamericanas. A través de una metodología de investigación-acción, se realizaron diversas acciones que condujeron a conocer posibles representaciones de las Pléyades desde las perspectivas de la ciencia erudita y una perspectiva vernácula particular, la etnia qom. Se realizaron intervenciones en distintos contextos educativos a través de diversos dispositivos de modo de abordar y relevar los conocimientos que circulan por las aulas sobre dicho cúmulo estelar. Posteriormente, se indagó el significado de las Pléyades a través de estudios lingüísticos, antropológicos y etnocientíficos con el fin de caracterizar los conocimientos vernáculos, y poder interpretar las representaciones propias de los actores involucrados. También, se apeló a los marcos teóricos particulares, la astronomía y la DCN, en especial las nociones alternativas de la didáctica de la astronomía para caracterizar las representaciones científicas escolares en relación con la enseñanza de las Pléyades.

De modo general, esta investigación se pregunta cómo pueden conectarse las diferentes interpretaciones de un mismo hecho
- fenómeno, por lo que se hace necesario conocer sus puntos de contacto. Claramente, los productos de esta investigación pueden contribuir con la generación de propuestas de enseñanza en contextos de educación intercultural bilingüe (EIB). A partir de la necesidad de propiciar la circulación de conocimiento de ciencias naturales significativo en contextos educativos multiculturales y multilingüísticos, hoy ausente en gran medida, se generó esta investigación didáctica que busca maneras de crear vínculos de significatividad entre los conocimientos científicos escolares (CCE) y los conocimientos tradicionales ancestrales (CET) (Molina y Mojica, 2013). Se tuvo en cuenta que en contextos escolares de multiculturalidad se focaliza en los procesos de enseñanza pues los puentes entre CCE y CET brindan la posibilidad de comunicación o diálogo entre las culturas, ya que se reconoce a un otro en la propuesta didáctica implicada considerando la coexistencia de diferentes cosmovisiones presentes en el aula, dado que la cultura y la lengua, en su carácter distintivo, han construido criterios sobre los cuales las sociedades humanas establecen sus identidades propias. Así, la ECI es un medio para el desarrollo de ciertas habilidades y conocimientos que permiten el empoderamiento de la gente del grupo social en el que se desenvuelve (Riveroll, 2010). Como consecuencia, la visibilización de puentes conceptuales entre las culturas intervinientes trae aparejado el cuestionamiento de las acciones didácticas docentes en la enseñanza de contenidos científicos y las propuestas escolares implicadas.

Las lógicas que estructuran esta investigación se enmarcan en otras lógicas que están determinadas sociohistóricamente y que, desde la perspectiva de la DCN, suelen estar fuera de los análisis. Llevar el problema de la ECI a un problema conceptual es un reduccionismo pues la situación social de la población qom 
es producto de una historia de sometimiento salvaje a un régimen capitalista que la despojó de sus territorios y modos de vida, entre otros vejámenes. Existe una discriminación estructural hacia los integrantes de las etnias aborígenes que permea las aulas y condiciona la materialización de las acciones. Si bien no se profundizará en los marcos y las acciones que caracterizan este aspecto, es conveniente visibilizar que atraviesa completamente la investigación y merece ser parte de la reflexión didáctica y sus consecuencias políticas.

Abordaremos el contexto general de la EIB en la provincia argentina de Chaco donde se localiza, en parte, la etnia qom. Por consiguiente, se definirán los principales elementos de la $\mathrm{ECl}$ en el contexto de nuestra investigación y valiéndonos de los marcos teóricos de la DCN se relacionarán las ideas previas (IP) con las cosmovisiones aborígenes. Seguidamente se vincularán las representaciones científicas y vernáculas sobre las Pléyades para abordar la metodología de investigación en la que se ancla nuestra investigación. Finalmente, se analizarán los resultados obtenidos y se presentarán las conclusiones del trabajo llevado a cabo.

\section{Antecedentes}

Los contenidos educativos a ser enseñados en las aulas de la Argentina dependen de su pertinencia territorial por ser un país federal y, a partir de la instauración y reconocimiento de la EIB como una de las 8 modalidades del sistema educativo argentino, el currículo escolar es permeable a modificaciones relacionadas con la interculturalidad. Es por eso que, en el año 2012, el Ministerio de Educación, Cultura, Ciencia y Tecnología de la Provincia del Chaco propuso un nuevo diseño curricular escolar de nivel primario y secundario mediante el que establece la diversidad sociocultural como modo de potenciar y permitir el aprendizaje del otro y con el otro pues la EIB no solo hace referencia a las culturas aborígenes, sino a las diferentes raíces étnicas, culturales, lingüísticas y religiosas dentro del aula posibilitando el encuentro entre culturas. Un ejemplo de ello es la cultura que, por un lado, porta el docente y, por otro, la del niño aborigen que está asociada con su lengua materna que este diseño curricular contempla, además del castellano-español.

Así, el currículo escolar de primaria y secundaria chaqueño establece que todas las lenguas son portadoras de cultura, y las aulas educativas son, por eso, espacios plurilingües y multiculturales en donde se deben reconocer, respetar y promocionar dichas lenguas y culturas. De esta forma, se promueve el diálogo y la preservación de la identidad colocando a ambas culturas en un lugar de valoración, cuestionando la hegemonía de la cultura dominante. Es por eso que se debe concebir una doble racionalidad para las propuestas de trabajo en el aula ya que se debe tener en cuenta que los niños de otras culturas poseen una racionalidad vernácula y otra científica (Ministerio de Educación, Cultura, Ciencia y Tecnología, 2012). 
Debido a esto, el sistema educativo provincial ha transitado por diferentes experiencias pedagógicas y por la formación de docentes aborígenes destinados a solucionar la barrera de comunicación. Los profesores interculturales bilingües tienen las mismas atribuciones que el docente tradicional y ambos se deben articular y complementar como pareja pedagógica. Sin embargo, en la práctica se observa que los docentes aborígenes en formación son castellanizados e instruidos únicamente en la cultura occidental, negando su propia cultura pues no existe una formación sistematizada que las vincule a ambas. Muchas veces estos docentes realizan funciones subordinadas al docente tradicional y como consecuencia no se realiza un trabajo cooperativo entre dicha pareja pedagógica.

El docente aborigen frecuentemente actúa como un mero traductor de su idioma por lo que la escuela es un terreno de tensiones culturales, donde entran en juego diferentes factores y actores sociales: pobreza y exclusión, por una parte, y docentes y estudiantes de orígenes diversos, por otra. Por lo dicho hasta aquí es posible afirmar que en la mayoría de los casos no existe enseñanza intercultural.

\section{Marco teórico}

\section{Elementos para definir una $\mathrm{ECl}$ en el contexto de nuestra investigación}

La implementación de la modalidad de EIB en la Argentina estuvo atravesada por múltiples tensiones y no ha logrado impactar significativamente en la educación de los pueblos originarios, atravesados por la desigualdad social y, por ende, educativa (Hirsch, 2010). Un factor determinante de su falta de impacto es la escasez de materiales didácticos multiculturales y multilingües. Otro es la ausencia de formación de los docentes, en especial, de los que están frente a aulas que reciben poblaciones culturalmente diversas, pero no únicamente. A todos estos factores se suma, en especial, el hecho de que la enseñanza de las ciencias naturales en la educación obligatoria se encuentra en una profunda crisis que se manifiesta a través de los escasos logros de aprendizaje de los estudiantes (Ministerio de Educación, Ciencia y Tecnología, 2007). El fin primario de la $\mathrm{ECl}$ es educar científicamente a una población con diversidad cultural y lingüística reconociendo que las comunidades indígenas han generado su propia visión de mundo, lo que condiciona la legibilidad de los conocimientos de otros orígenes culturales diferentes. Es necesario señalar que a estas dificultades debe sumarse la situación de exclusión a la que están sometidas las poblaciones indígenas que transitan las escuelas, y también la falta de propuestas de enseñanza y de materiales didácticos significativos para las aulas multiculturales.

La enseñanza científica intercultural propone un modelo dialógico intercultural desde una mirada pluralista, que permita validar los sistemas de conocimiento generados por las comunidades; a través del diálogo se busca transformar identidades y prácticas (Riveroll, 2010). La ECI propone un encuentro entre culturas para generar prácticas educativas significativas para las poblaciones para las que se destinan. Por eso es clave en este trabajo apelar a marcos teóricos de la DCN que no han desarrollado una línea específica de interculturalidad. En este sentido, cuando un objeto de estudio no se inserta en una línea de investigación existente es necesario definirlo a través de algunas de sus fuentes teóricas (Bonan, 2005). En el ámbito de nuestro problema, se acudirá a la etnoastronomía, la lingüística y la antropología ya que brindan aportes valiosos para caracterizar algunos aspectos de la ECI. Estos enfoques contribuyen con la generación 
de vínculos entre las cosmovisiones aborígenes y la ciencia occidental, pensando el diálogo multicultural destinado a las aulas.

\section{De las IP a las cosmovisiones aborígenes}

Una de las líneas de investigación más desarrolladas en la DCN es la de las IP, que alerta sobre el hecho de que los estudiantes traen sus propias ideas a las aulas, mediante las cuales interpretan y explican los fenómenos naturales que se enseñan en la escuela. En pocos casos, estas concepciones concuerdan con los nuevos conocimientos enseñados en clase, generalmente existen contradicciones entre sus creencias y las ideas científicamente aceptadas. Se han publicado diversos catálogos sobre las IP de los estudiantes en diversas áreas del conocimiento, pero siempre de estudiantes pertenecientes a la cultura occidental sin tener en cuenta culturas identitarias diferentes. Según Camino (2005), las cosmovisiones aborígenes, desde el punto de vista heurístico, funcionan para dar coherencia y significado a los diversos hechos e informaciones, implícitamente priorizando y evaluando, caracterizando y criticando. Este mismo autor describe un punto de vista generativo, mediante el cual, las cosmovisiones no solo nos dicen cómo tratar con la información en el mundo, sino que también implican nueva información, presuposiciones, creencias, etc., pues son activas fuentes de comprensión más que filtros o lentes a través de los cuales ver la realidad.

Para abordar esta problemática, a través de nuestra investigación anclamos en la cultura qom, una de las etnias aborígenes que habita el Gran Chaco Argentino. Con este fin, fue necesario profundizar en su cosmovisión a través de fuentes antropológicas (Tola, 2012). Así supimos que es una cultura de transmisión oral, no fragmentada, como sí lo es la ciencia occidental, y que asume el universo como un todo. A través de fuentes etnocientíficas pudimos conocer las representaciones qom sobre las Pléyades, con el fin de encontrar vínculos entre la ciencia erudita y el conocimiento vernáculo.

\section{Las Pléyades como temática propuesta para vincular las representaciones científicas y étnicas}

Desde la perspectiva científica, es posible caracterizar a las Pléyades como un cúmulo abierto o grupo de estrellas sin estructura y asimétrico, visible a ojo desnudo en el cielo nocturno. Posee un lugar privilegiado en la mitología griega y está situado a un costado de la constelación de Tauro. Las Pléyades son un conjunto de estrellas muy jóvenes ubicadas a una distancia aproximada de 440 años luz de la Tierra y se encuentran contenidas en un espacio de treinta años luz (Bouy, 2015). Se formaron hace alrededor de 100 millones de años, a partir de un colapso de una nube de gas interestelar. El diámetro aproximado del cúmulo es de 12 años luz, está formado por casi 500 estrellas. Las más grandes y brillantes son de color blanco-azulado y de un tamaño cercano a cinco veces 
el tamaño del Sol. Dependiendo de las condiciones atmosféricas, ocho de ellas pueden ser observadas a simple vista (figura 1).

Las civilizaciones más antiguas interpretaron que el universo era solo lo que se veía a ojo desnudo en el cielo estelar, estas ideas generaron muchas suposiciones teñidas de relatos e historias. Así, la observación sistemática fue útil para explicar fenómenos cotidianos, para muchas culturas amerindias las Pléyades fueron de suma importancia ya que su movimiento en el cielo nocturno da cuenta del ciclo anual y de la productividad (López, 2008).

Según un autor qom (Sánchez, 2010), mediante la observación nocturna estelar lograron establecer un calendario basado en sus movimientos vistos desde la Tierra. Es importante destacar que no toman como referencia los meses lunares ni el curso del Sol, pues consideran a las estrellas como dioses y describen sus orígenes mediante relatos en los que se explican sus influencias sobre los sucesos terrenales. Uno de los principales es el titulado "La hija del Siete Estrellas se casa con el Pájaro Carpintero", en el que se describen los estratos del cielo (Piguem), la tierra (Alhua) y el agua o submundo (Etaxat), habitados por seres de poder que influyen sobre la vida cotidiana de las personas. La comunidad qom transmite sus costumbres, cultura y cosmovisión de forma oral a través de sus relatos con estructuras lingüísticas coherentes, complejas y armónicas. Es necesario analizarlos y comprenderlos por ser una de las formas de educar a sus hijos, de transmitir los cuidados de su salud, el manejo de su economía y sus creencias religiosas, basadas en tótems celestiales presentes en esos relatos.

\section{Metodología}

La investigación se materializó a través de una metodología de investigación acción.

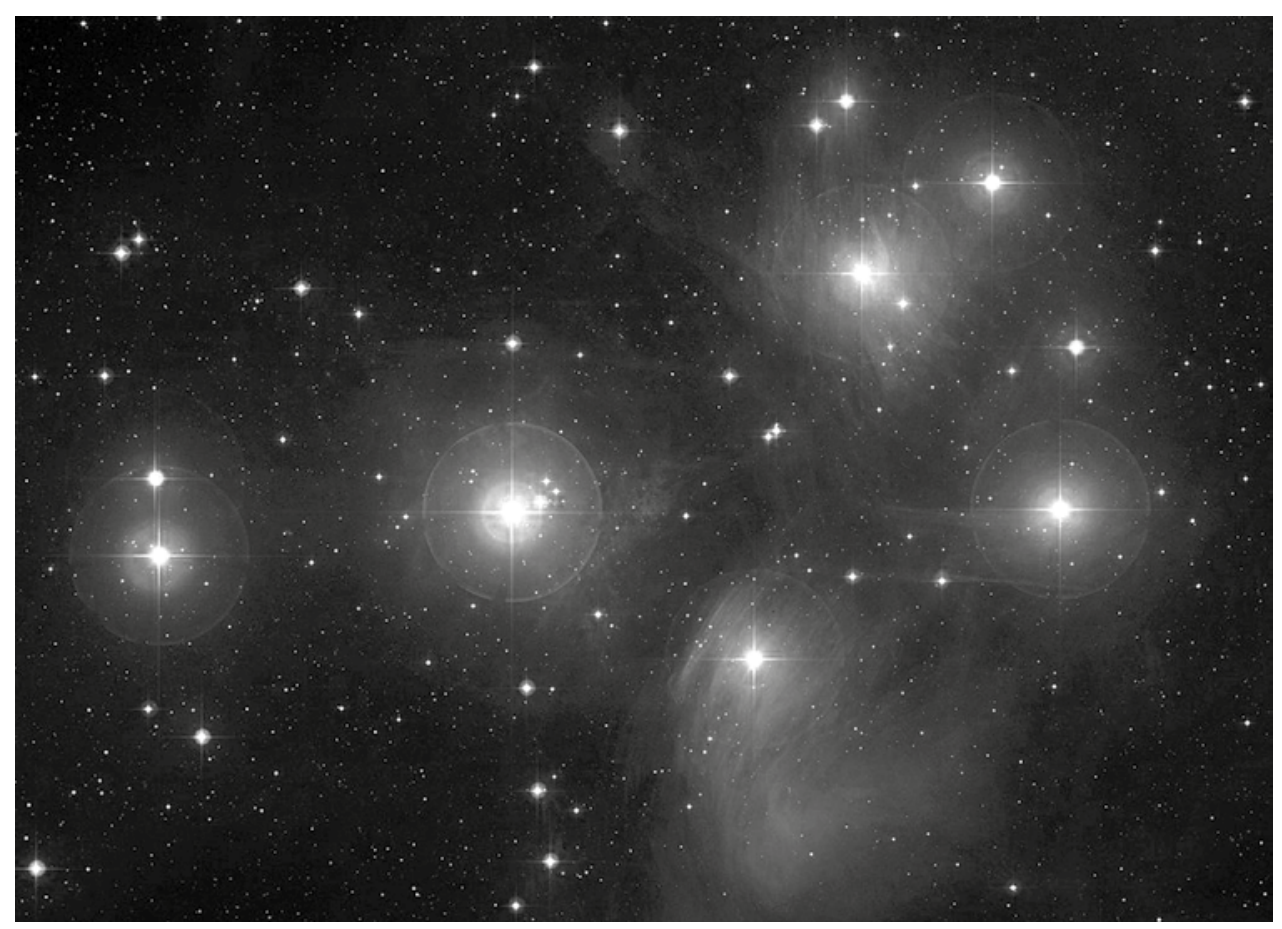

Figura 1. Imagen compuesta en color de las Pléyades del Digitized Sky Survey

Fuente: NASA, ESA, AURA/Caltech, Palomar Observatory. 
El proceso se pensó como una intervención que pudiera responder las siguientes preguntas: ¿̇cómo relevar las representaciones vernáculas sobre las Pléyades de estudiantes qom que circulan en una escuela secundaria rural? ¿Poseen todos las mismas representaciones? A continuación, se planificaron los pasos y estrategias para llevar a cabo la acción y evaluar sus resultados; y, de esta manera, comprender la formulación y evaluación del problema planteado en una situación educativa. Se obtuvieron datos a través de observaciones, entrevistas, análisis de documentos y registros de audio. Se elaboraron categorías de análisis a medida que se desarrolló el estudio.

Específicamente, se abordaron contextos escolares rurales (figura 2), se relevaron las representaciones de diversos actores sobre el cielo, en especial sobre las Pléyades desde una perspectiva multicultural, se registraron y evaluaron todas las acciones a la luz de los objetivos trazados.

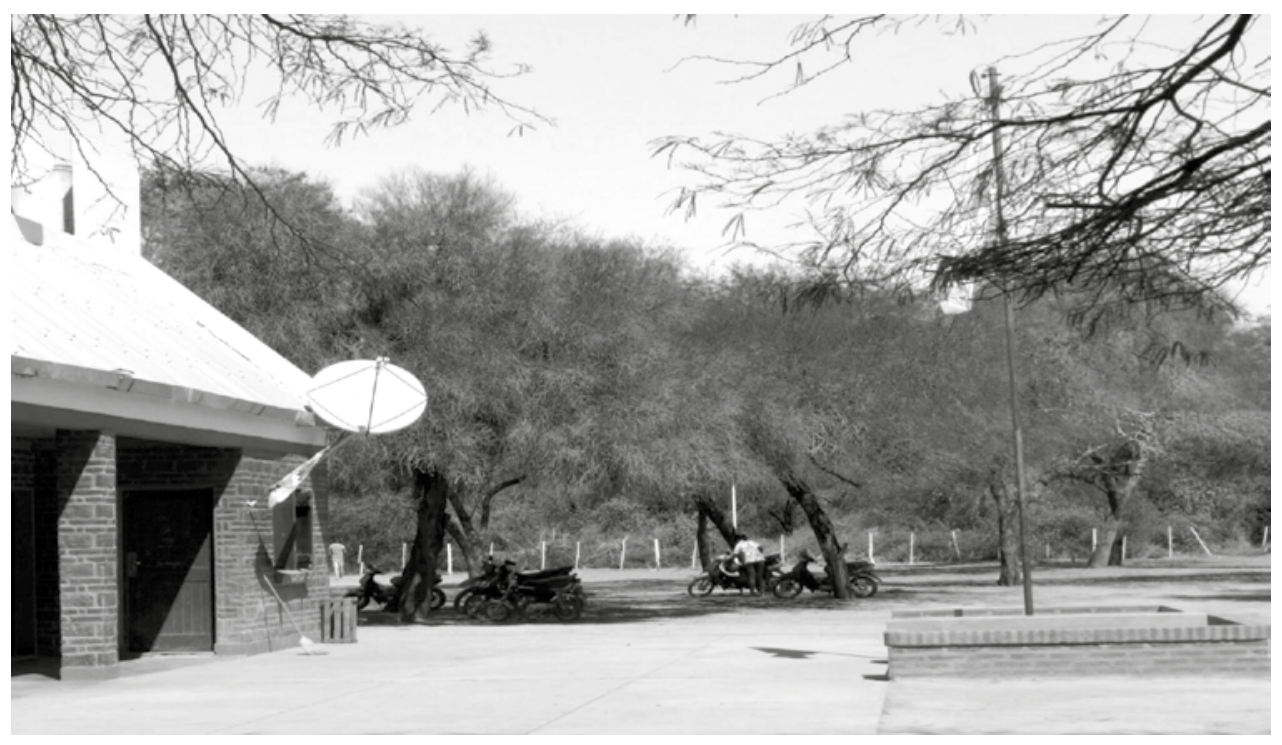

Figura 2. Contextos escolares rurales de la Provincia de Chaco (Argentina)

Fuente: fotografías tomadas durante la investigación.

Recordemos que el objetivo general de las actividades diseñadas es indagar las representaciones vernáculas sobre las Pléyades, para ello se realizó una intervención que condujo a un diagnóstico preliminar. Esta fue llevada a cabo en la Escuela de Enseñanza Media n. ${ }^{\circ} 168$ y sus dos anexos. La cantidad de estudiantes es de aproximadamente 100 en la sede central y de entre 40 y 60 en los anexos. Se trabajó con grupos de 30 estudiantes en cada una de las intervenciones realizadas. Es relevante mencionar que las consignas fueron discutidas hasta último momento y modificadas permanentemente a medida que se implementaba el relevamiento. Se buscó que las actividades fuesen lo suficientemente abiertas como para que permitieran emerger las representaciones de los estudiantes, en algunos casos induciendo la aparición de conocimientos ancestrales. 
Las actividades se implementaron de manera tal que la comunicación no se basara únicamente en el lenguaje oral. Para ello se utilizó una selección de 3 minutos de un dibujo animado que describe diferentes representaciones culturales sobre las Pléyades, imágenes diversas y elementos pictóricos para realizar un collage, un software de simulación del cielo, el Stellarium y telescopios caseros (figura 3).

Nos aseguramos de que una de las actividades del relevamiento tuviera una instancia de producción que pudiera registrarse. Presentamos brevemente las actividades planificadas:

\section{Actividad 1: Presentación de los participantes.} Se presentan los estudiantes de la escuela, luego los docentes intervinientes y se explica de forma oral los objetivos formativos de las actividades a realizar.

\section{Actividad 2: Proyección de un fragmento} de la serie Cosmos.

Se proyecta un fragmento de la serie Cosmos que muestra diferentes explicaciones sobre la formación de la constelación de las Pléyades.

Luego de proyectar el video se intenta dialogar con los estudiantes acerca del significado de lo que vieron. Algunas preguntas que pueden ayudar: ¿̇qué nos muestra el video? ¿Conocen el término constelación? ¿ Conocen alguna constelación? ¿Alguna en particular que se observe desde el cielo de Miraflores? ¿Qué saben o qué conocen del cielo?

Actividad 3: Realización de un collage.

A partir de lo observado en el video y de lo dialogado entre todos, se pide a los estudiantes que representen mediante un dibujo, collage, frases, etc.; ¿̇qué ves cuando miras al cielo? Siendo la respuesta a esta pregunta de creación y construcción grupal.

\section{Actividad 4: Interacción con el simulador} de cielo Stellarium.

Sabiendo que la mayoría de los estudiantes poseen netbooks con el programa Stellarium instalado, proponemos en primera instancia mostrarles cómo funciona. Luego, buscamos con ellos el cielo de Miraflores para luego salir al aire libre y ver si pueden identificar alguna constelación representada en el programa.

Actividad 5: Manipulación de telescopios caseros. En esta última actividad se trabaja con telescopios caseros, realizados con botellas plásticas, lentes de lupas y de cuenta hilos. Previamente a otorgarles dichos telescopios a los estudiantes, se realizan las siguientes preguntas de forma oral: ¿̇saben qué es un telescopio? ¿̇Para qué sirve? ¿Cómo funciona?

Una vez fuera del aula, se les brinda los telescopios caseros a los estudiantes, para que observen a través de ellos. El principal objetivo de esta actividad es mirar y luego de un tiempo de observación, poner en común mediante el diálogo cómo ven a través del telescopio, qué observaron, etc.

\section{Actividad 6: Cierre y conclusiones grupales.} Se retoma la primera actividad y se indaga de forma oral a través de una puesta en común grupal: Żcambiarías o agregarías algo a tu trabajo inicial después de haber mirado a través del telescopio? ¿Qué cambia al colocar el telescopio casero entre tu visión y el cielo? ¿En qué cambió tu percepción al mirar a través de él?

\section{Resultados y análisis}

La presencia de elementos de la cultura qom en la propuesta promovió su emergencia en las expresiones de los jóvenes. Como resultado de la actividad de registro se obtuvieron 31 láminas. Es importante recordar que en la cosmología qom los seres vivientes y de poder transitan por tres planos que conforman el mundo: el cielo (Piguem), la tierra (Alhua) y el agua o submundo (Etaxat) y esto es posible gracias a sus transformaciones corporales.

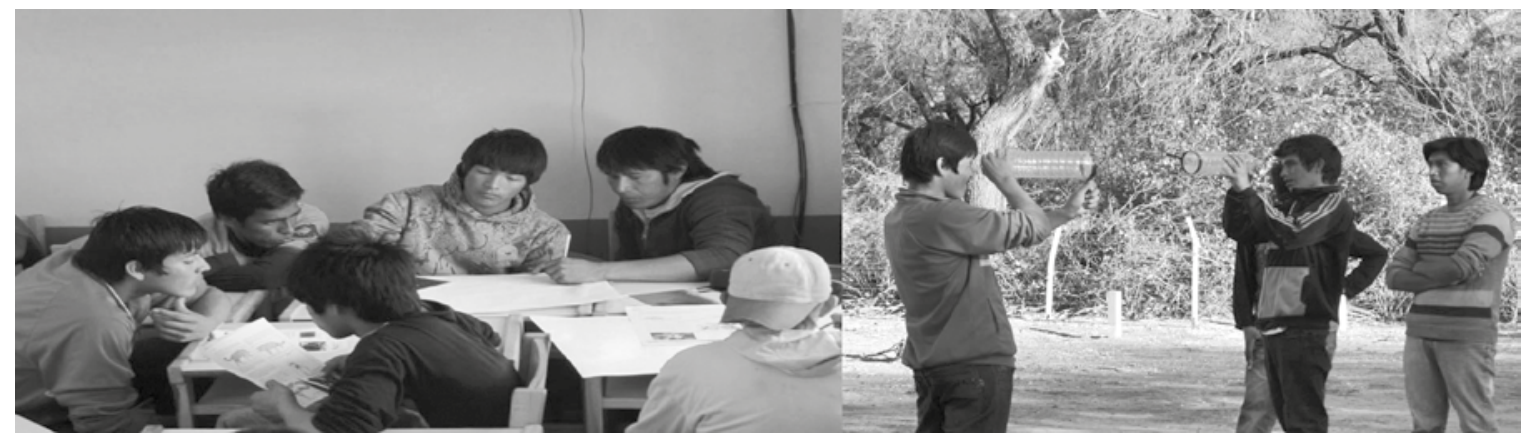

Figura 3. Grupos de estudiantes trabajando en las consignas planteadas

Fuente: fotografías tomadas durante la investigación. 
Generalizando, cabe destacar que los resultados alcanzados exhiben elementos de su cosmovisión pues, en los collages realizados por los estudiantes en respuesta a la pregunta planteada: "¿Qué ves cuando miras al cielo?", no solo aparecen estrellas o cuerpos celestes dibujados, sino también animales, casas y personas. Algunos elementos se repiten como el cúmulo abierto de las Pléyades también Ilamado Siete Cabritos o las Siete Hermanas; las Tres Marías, Ñandúes y otros animales relacionados con el contexto chaqueño (figura 4).
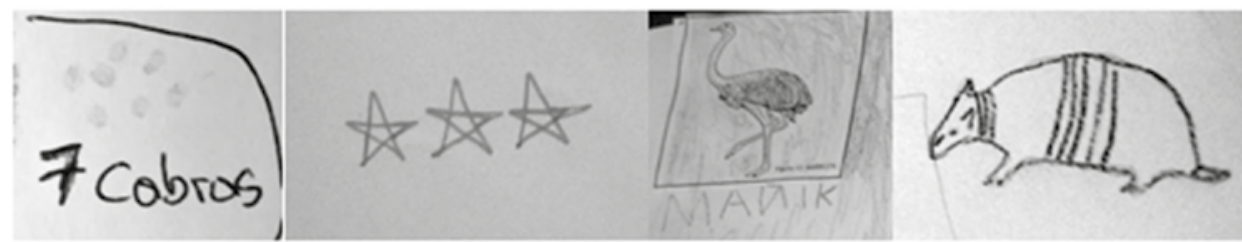

Figura 4. Dibujos obtenidos en el primer ciclo de investigación, en ellos aparecen las Pléyades o Siete Cabritas, las Tres Marías, un ñandú (Mañik) y un tatú carreta

Fuente: fotografías tomadas durante la investigación.

Se efectuó una estadística sobre las apariciones de elementos que fueron representados por los estudiantes, ya sea a través de dibujos, frases o palabras y observando en las láminas los dibujos que tienen más repeticiones (tabla 1).

Tabla 1. Valores obtenidos en la muestra. Se explicitan los dibujos y anotaciones realizados por los estudiantes ordenado de mayor a menor según su número de repeticiones en cada lámina

\begin{tabular}{|c|c|}
\hline $\begin{array}{l}\text { Dibujo o } \\
\text { Palabra }\end{array}$ & $\begin{array}{l}\text { Número de } \\
\text { repeticiones }\end{array}$ \\
\hline Luna & 33 \\
\hline Estrellas & 31 \\
\hline Sol & 18 \\
\hline $\begin{array}{l}\text { Frases y Palabras } \\
\text { Humano/s }\end{array}$ & 17 \\
\hline Tres Marías & 12 \\
\hline Nubes & 10 \\
\hline Animales & 9 \\
\hline Planetas & 7 \\
\hline $\begin{array}{l}\text { Árboles y monte } \\
\text { Las Pléyades }\end{array}$ & 6 \\
\hline Nandú & \multirow{6}{*}{4} \\
\hline $\begin{array}{l}\text { Lucero de la } \\
\text { mañana }\end{array}$ & \\
\hline $\mathrm{Pez} /$ Peces & \\
\hline Yaguareté & \\
\hline Telescopio & \\
\hline Estrella Fugaz & \\
\hline
\end{tabular}

\begin{tabular}{|c|c|}
\hline $\begin{array}{l}\text { Dibujo o } \\
\text { Palabra }\end{array}$ & $\begin{array}{l}\text { Número de } \\
\text { repeticiones }\end{array}$ \\
\hline Chuña & \multirow{7}{*}{3} \\
\hline Casa & \\
\hline Perros & \\
\hline Tatú & \\
\hline Arcoiris & \\
\hline Sistema Solar & \\
\hline Agua & \\
\hline $\begin{array}{l}\text { Qasoxonaxa } \\
\text { (Dueño De la } \\
\text { Lluvia) }\end{array}$ & \multirow{7}{*}{2} \\
\hline La Cruz del sur & \\
\hline Vizcacha & \\
\hline Eclipses & \\
\hline Avión & \\
\hline Aves & \\
\hline Helicóptero & \\
\hline
\end{tabular}

\begin{tabular}{|l|l|}
\hline Dibujo o Palabra & $\begin{array}{l}\text { Número de } \\
\text { repeticiones }\end{array}$ \\
\hline Mariposa & \\
\hline Flor & \\
\hline Fuego & \\
\cline { 1 - 1 } $\begin{array}{l}\text { Moxosagan } \\
\text { (Dueño de las } \\
\text { nubes) }\end{array}$ & \\
\hline Garza & \\
\cline { 1 - 1 } $\begin{array}{l}\text { Dueño de las } \\
\text { Rayas }\end{array}$ & \\
\hline Carancho & \\
\hline Puma & \\
\hline Lagartija \\
\hline Orión \\
\hline Camino \\
\hline Relámpagos \\
\hline Globo Aerostático \\
\hline Mapa Estelar \\
\hline
\end{tabular}

Fuente: elaboración propia. 
Como el objetivo de este trabajo de investigación es develar qué puentes conceptuales existen en torno a las Pléyades, basaremos el análisis de resultados en este grupo de estrellas. Si observamos la tabla de la figura 5, las encontramos con un valor de frecuencia igual a 6, y forman parte de los elementos de importancia en el cielo. Las Pléyades Ilevan el nombre de Dapichi' en la cultura qom, esta comunidad llama de la misma manera a las flores del clavel del aire, que florece en primavera, época que coincide con la aparición de las Pléyades en el horizonte, lo que en astronomía se denomina salida helíaca. La morada del Dapichi' es observada como la región celestial donde este ser de poder vive junto a sus hijas y de allí observa el devenir de los seres humanos. Como todas sus hijas son mujeres, se lo considera como un protector de ellas (Sánchez, 2010). Es por eso que se lo ve como un líder entre las estrellas, que da inicio al ciclo de fecundidad, y cuya aparición en el horizonte hace descender las primeras heladas. Estas últimas se vinculan con el cielo y a su fertilidad, ya que son la garantía de la posterior abundancia en la tierra durante la primavera (López, 2008).

En las entrevistas realizadas, los estudiantes manifestaron conocer el relato "La hija del Siete Estrellas se casa con el Pájaro Carpintero" asociado al Dapichi'. Lo describen como un ser de respeto y poder, que vive en una morada muy helada, padre de siete hijas, una de las cuales tiene el poder de hacer madurar los frutos del algarrobo con el fin de abastecer a la comunidad qom.

El modo en el que los qom observan a las Pléyades en el cielo es compatible con la concepción astronómica conocida como esfera celeste, ya que su aparición en el horizonte y movimiento son indicadores para la comunidad. Este es uno de los grandes vínculos develados entre los conocimientos vernáculos y científicos de este trabajo. A su vez podemos relacionar la aparición de las Pléyades con las estaciones del año, lo que convierte a esa constelación en más que un grupo de estrellas que se mueven en el cielo nocturno. También se puede afirmar que se asocian con una serie de relatos que subsumen dentro de sí la constitución del orden espacial para los qom, que consideran la Tierra plana, estratificada, con seres que se transforman de humanos a "no humanos" cuando pasan de un estrato a otro. Tal como fue mencionado en el marco teórico el estrato superior es el cielo (Piguem), le sigue "hacia abajo" la tierra (Aluha) y, por último, el agua (Etaxat). Cada uno de estos estratos, a su vez, se estratifica. Los estratos suelen representarse en planos paralelos entre sí. Desde la didáctica de la astronomía, el estudio clásico de Nussbaum (1989), La Tierra como cuerpo cósmico alude a esta estratificación como un estadio anterior a la constitución de la tierra esférica con una atracción gravitatoria radial.

\section{Conclusiones}

Las actividades planteadas para relevar la información sobre las Pléyades resultaron potentes para el fin que nos propusimos. El proceso en sí mismo resultó productivo: generamos actividades a modo de hipótesis que a medida que se ponían en acción se iban configurando. Las regularidades en las producciones de los estudiantes fueron las pistas que nos condujeron a develar algunos elementos de su cultura, lo que disparó un proceso de búsqueda de información a través de las fuentes, la etnoastronomía, la antropología y la lingüística. Este primer trabajo de campo nos llevó a buscar bibliografía bilingüe castellano-qom para ampliar el sentido de la educación intercultural incluyendo su expresión vernácula. Los pulsos del pensamiento hegemónico no consciente 
que se materializan en nuestras acciones se ven interpelados por el diálogo con otros actores involucrados en los ámbitos de interculturalidad que va transitando el grupo de investigación.

Mediante este trabajo de investigación, se logró profundizar sobre las representaciones vernáculas y científicas de las Pléyades en la cultura qom, ya que este cúmulo abierto estelar no es solo un indicador del comienzo de la época de fecundidad y la finalización de la estación invernal, sino que también está relacionado con relatos de los antiguos y es una de las figuras principales del cielo qom. Así, el cielo se funde como parte del paisaje y hay una construcción cultural de la mirada del mismo pues en él no solo intervienen los sucesos celestes, sino que estos están ligados directamente con los fenómenos terrenales y acuáticos.

Las representaciones vernáculas sobre las Pléyades si bien aparecieron no lo hicieron con una frecuencia muy alta. Esto nos dio una pauta de la poca circulación de los relatos tradicionales o bien de su ocultamiento por parte de los estudiantes a modo de mecanismo de preservación.

Gracias al análisis de resultados, también encontramos otros elementos de gran importancia para la cultura vernácula los cuales brindan un aporte relevante para le ECl, pues al conocer las concepciones vernáculas de la cosmovisión qom se pueden tender puentes conceptuales que la vinculen con la ciencia occidental. Una vez reconocidos estos vínculos que funcionan de nexo entre una cultura y la otra el terreno es fértil para la elaboración de materiales didácticos.

La mirada crítica no hegemónica nos permitió desnaturalizar la discriminación histórica a la que están sometidos los qom en los ámbitos sociales en los que se desenvuelven. En muchas ocasiones, por más buena disposición que tuviera un agente educativo no qom, era partícipe de situaciones discriminatorias. Incluso nosotros mismos en retrospectiva reconocemos situaciones inconscientemente homogeneizantes respecto de la cultura vernácula. De todos modos, nuestra actitud abierta y sensible a estas cuestiones va dando lugar a avanzar en la construcción de la ECl.

\section{Agradecimientos}

Este trabajo se realiza en parte con aportes del Proyecto UBACyT20020090200350BA (Grupos Consolidados). Formación e investigación en Educación Ambiental: Reflexiones e impacto. Instituto de Investigaciones CEFIEC-FCEN-UBA. Aprobado y Financiado. 


\section{Referencias}

Bonan, L. (2005). Cómo se define un problema de investigación en Didáctica de las Ciencias Naturales. En G. Foriti y P. Moglia, La formación docente y la investigación en didácticas específicas [Cuadernos del CEDE]. San Martín: UNSAM.

Bouy, H. (2015). The Seven Sisters Dance. I. Empirical isochrones, luminosity, and mass functions of the Pleiades cluster. Astronomy \& Astrophysics, 148, 1-17.

Camino, N. (2005). Génesis y evolución del concepto de gravedad: construcción de una visión de universo (Tesis de doctorado). Facultad de Humanidades y Ciencias de la Educación. Universidad Nacional de La Plata.

Hirsch, S. (2010). Pensando la educación cultural bilingüe en contextos pluriétnicos y plurilingüísticos. En S. Hirsch y A. Serrudo, La educación intercultural bilingüe en Argentina. Identidades, lenguas y protagonistas (pp. 121 -148). Buenos Aires: Noveduc.

López, A. (2008). Las Pléyades, el sol y el ciclo anual entre los mocovíes. VI Congreso Argentino de Americanistas (1 -20). Astronomía Cultural, Buenos Aires.
Ministerio de Educación, Ciencia y Tecnología (2007). Mejorar la enseñanza de las ciencias y la matemática: una prioridad nacional. Informe y recomendaciones de la comisión nacional para el mejoramiento de la enseñanza de las ciencias naturales y la matemática.

Ministerio de Educación, Cultura, Ciencia y Tecnología (2012). Currículo para la Educación Primaria del Chaco, Resistencia. Recuperado de http://www.dirdocumentacion.com.ar.

Molina, A., y Mojica, L. (2013). Enseñanza como puente entre conocimientos científicos escolares y conocimientos ecológicos tradicionales. Magis, Revista Internacional de Investigación en Educación, 6(12), 37-53.

Nussbaum, J. (1989). La Tierra como cuerpo cósmico. En Ideas científicas en la infancia y la adolescencia (cap. 9). Madrid: Morata.

Riveroll, L. (2010). Educación intercultural bilingüe. Una educación científica para la interculturalidad. Congreso Iberoamericano de Educación Metas 2021. Organización de Estados Iberoamericanos, Buenos Aires.

Sánchez, O. (2010). Rasgos culturales Tobas. Sáenz Peña: Librería de la Paz.

Tola, F. (2012). Yo no estoy solo en mi cuerpo. Buenos Aires: Biblos.

\section{Para citar este artículo}

Chadwick, G., y Bonan, L. (2018). Educación científica intercultural: tendiendo puentes conceptuales sobre las Pléyades en el Gran Chaco. Tecné, Episteme y Didaxis: TED, 43, 17-29. 
